\title{
Risk factors for human papillomavirus infection among women in Portugal: The CLEOPATRE Portugal Study
}

\author{
Angela Pista $^{\text {a,* }}$, Carlos F. de Oliveira ${ }^{\text {b }}$, Maria J. Cunha ${ }^{\text {c }}$, Maria T. Paixao a , Odete Real ${ }^{\text {d; }}$ \\ CLEOPATRE Portugal Study Group ${ }^{1}$
}

a Department of Infectious Diseases, National Institute of Health, Lisbon, Portugal

b Gynecology Department, University Hospital, Coimbra, Portugal

c Scientific Affairs Department, Sanofi Pasteur MSD-Portugal, Amadora, Portugal

d Cytopathology Laboratory Dr Odete Real Lda, Coimbra, Portugal

\section{A R T I C L E I N F O}

\section{Article history:}

Received 27 October 2011

Received in revised form 2 March 2012

Accepted 12 April 2012

\section{Keywords}

Cervical infection

Human papillomavirus

Portugal

Prevalence

Risk factor

\begin{abstract}
A B S T R A C T
Objective: To investigate demographic, socioeconomic, lifestyle, and medical factors that might predispose women to cervical human papillomavirus (HPV) infection. Method: A cross-sectional population-based study was performed. Women aged 18-64 years who attended selected obstetrics and gynecology or sexually transmitted disease (STD) clinics in mainland Portugal between February 2008 and March 2009 were recruited, according to an age-stratified sampling strategy. Liquid-based cytology samples were analyzed centrally for HPV genotype and for cytologic features. Univariate and multivariate logistic regression analyses identified risk factors for HPV infection. Results: Among the 2326 women evaluated, the crude prevalence of HPV infection was $19.4 \%$. Lifetime number of sexual partners was a strong predictor of HPV infection (odds ratio 5.44 for $5-10$ partners versus 1 partner; $P<0.001$ ). Other risk factors were young age (particularly among women aged 20-24 years; $P<0.001)$; country of birth other than mainland Portugal $(P=0.002)$; education up to secondary school level $(P=0.010)$; smoking history ( $\leq 10$ years; $P=0.004)$; and any STD in the past 12 months $(P=0.052)$. Conclusion: Data from the present study may aid identification of women at increased risk of HPV infection and target prevention strategies.
\end{abstract}

Trial registration: National Commission of Data Protection (CNPD) registration number 5346/2007; Sanofi Pasteur MSD study number HPV-E05.

(c) 2012 International Federation of Gynecology and Obstetrics. Published by Elsevier Ireland Ltd. All rights reserved.

\footnotetext{
* Corresponding author at: Instituto Nacional de Saúde, Avenida Padre Cruz, 1649-016 Lisbon, Portugal. Tel.: + 351 217519213; fax: + 351217526498.

E-mail address: angela.pista@insa.min-saude.pt (A. Pista).

CLEOPATRE Portugal Study Group members: CENTRO HOSPITALAR DE VILA NOVA DE GAIA: Angelina Tavares; Ana P. Santos; Isabel Santos; Teresa Brito; Elisa Paredes; Graça Ramalho; Emília Cunha; Claudina Carvalho; Eugénia Rocha; Rosário Pedro. CENTRO DE SAÚDE DA LAPA: Jacinta Azevedo; Irene Santo; Inês Costa. HOSPITAL CUF DESCOBERTAS: Maria da Conceição Telhado; Mariana Loureiro; Cristina Horgan; Elisete Cortes; Idalina Marques; Sofia Alegra; Maria do Carmo Sena; Jorge Lima; Patrícia Teixeira; Elisabete Afonso. HOSPITAL DE BEJA: Isabel Reina; Ana P. Ladeira; Maria J. Fernandes; Helena Fitas; Ana S. Reforço. HOSPITAL DE FARO: Maria A. Pacheco; Olga Viseu; Eunice Capela; Ângela Ferreira; Ivete Gigante. HOSPITAL DE GUIMARÃES: José M. Furtado; Pedro Vieira de Castro; Conceição Príncipe; António Almeida e Silva; Maria J. Pires; Maria J. Bastos; Teresa Monteiro; Elizabete Castela. HOSPITAL SÃO JOÃO: Jorge Beires; Carlos A. Rocha; Ana S. Fernandes; João P. Neves; Pedro Baptista; Diana Arteiro; Joana Amaral; Laurinda Ribeiro; Lucília Azevedo. HOSPITAIS DA UNIVERSIDADE DE COIMBRA: Fernando Mota; Paulo Moura; Isabel Torgal; Ondina Jardim; Augusto Regedor; Clara Morais; Ermelinda Sobral; Fernanda Neves; Francisco Falcão; José Órfão; Luis Almeida e Sousa; Margarida Tavares; Maria G. Varela; Maria Nascimento; Natália Amaral; Rui Lagarto; Teresa Bombas; Teresa Rebelo; Eugénia Andrade; Juvelina Domingues; Elsa Filipe. MATERNIDADE ALFREDO DA COSTA: Jorge Borrego; Adelaide Vitorino; Teresa Paula; Fátima Palma; Paula Maia; Ana Fatela; Daniela Sobral; Paula Pereira; Isabel Grilo; Sara Mendonça. UNIVERSIDADE DE TRÁS-OS-MONTES E ALTO DOURO: Zélia Gomes; Paula C. Lopes. INSTITUTO NACIONAL DE SAÚDE: Nuno Verdasca; Ana Oliveira; Paulo Nogueira; Eleonora Paixão; Ausenda Machado. SANOFI PASTEUR PORTUGAL: Sofia Santos.
}

\section{Introduction}

Infection with human papillomavirus (HPV) is an obligatory event for the development of cervical cancer [1]. Specific HPV genotypes (HPV 6, 11, 16, and 18) are responsible for the majority of anogenital diseases caused by this virus among women $[2,3]$.

Infection with high-risk HPV genotypes (HPV 16, 18, 31, 33, 35, 39 , $45,51,52,56,58$, and 59 ) in the presence of risk factors that promote the persistence of infection precedes the development of precancerous lesions of the cervix. These risk factors are either biological, such as co-infections with other sexually transmitted diseases (STDs), or behavioral, such as sexual habits. A consistent association has been demonstrated between an increased lifetime number of sexual partners and HPV infection among women [4-6]. However, a number of other factors, such as young age at first sexual intercourse, use of oral contraceptives, and smoking have shown inconsistent associations with HPV infection [6-9].

The CLEOPATRE (Cervical LEsions Observed by PApillomavirus Types - a Research in Europe) studies aim to provide a better understanding of the epidemiology of HPV infection across Europe. Based on data for a sample of women attending gynecology/obstetrics or 
STD clinics, the CLEOPATRE Portugal study has estimated the overall, age-stratified and type-specific prevalence of cervical HPV infection in women aged 18-64 years living in mainland Portugal [10]. The objective of the present analysis was to assess demographic, socioeconomic, lifestyle, and medical factors that may predispose women enrolled in the CLEOPATRE Portugal study to cervical HPV infection.

\section{Materials and methods}

The CLEOPATRE Portugal study was a population-based, observational, cross-sectional study conducted between February 1, 2008, and March 31, 2009, across the 5 Regional Health Administrations of mainland Portugal. The study methods have been described in detail previously [10]. Briefly, women aged 18-64 years attending selected obstetrics and gynecology or STD clinics and who had not been vaccinated against HPV were invited to participate in the study. Pregnant women for whom a Papanicolaou test was not contraindicated were eligible to participate. Virgins and women with a history of abnormal cytology in the 12 months before the enrolment visit, who had undergone a hysterectomy and or who had undergone a cone excision or loop electrosurgical excision procedure in the 24 months before the enrolment visit, were excluded from participation. The protocol was approved by the National Institute of Health (INSA), which was the public entity responsible for the present epidemiologic study. Study procedures were approved by the Ethics Committee of each collaborating Center. All participants were informed about the procedures and data handling, and a signed consent form was obtained prior to any study procedure.

After enrollment, demographic, socioeconomic, lifestyle, and medical details were collected and recorded in a case report form. Liquidbased cytology samples were collected during a gynecologic examination and sent to a centralized laboratory for HPV genotyping and cytologic evaluation. Genotyping was performed using the CLART HPV 2 assay (GENOMICA, Madrid, Spain). This methodology uses biotinylated primers that amplify a fragment of $450 \mathrm{bp}$ within the HPV L1 ORF region. Co-amplification of an 892-bp region of the CFTR gene and a 1202-bp fragment of a transformed plasmid provides a control to ensure DNA adequacy and PCR efficiency. Amplicons are detected by hybridization in a low-density microarray containing triplicate DNA probes specific to 35 genotypes (HPV 6, 11, 16, 18, $26,31,33,35,39,40,42,43,44,45,51,52,53,54,56,58,59,61,62$, $66,68,70,71,72,73,81,82,83,84,85$ and 89). Semi-quantitative results can be obtained in an automatic reader. DNA was isolated from $1 \mathrm{~mL}$ of cellular suspension using the NucliSENS easyMAG (BioMerieux, Boxtel, The Netherlands) system, as specified in the manufacturer's instructions. Cytologic evaluation was performed on the liquid-based samples using the ThinPrep method (Cytyc, Boxborough, MA, USA), and cytology slides were classified according to the Bethesda System.

Statistical analyses were undertaken at the Department of Epidemiology of INSA using Basic and Complex Samples from SPSS version 17.0 (IBM, Armonk, NY, USA), as described previously [10]. Univariate logistic regression analysis was conducted to evaluate the association between HPV infection (dependent variable) and potential risk factors (explanatory variables). The potential risk factors evaluated were age; country of birth; level of education; smoking habits; age at first sexual intercourse; contraceptive use; lifetime number of sexual partners; any circumcised sexual partner; history of cervical intraepithelial neoplasia; any STD in the past 12 months; and current status of the immune system. The relative risk estimation (odds ratio [OR] with $95 \%$ confidence interval $[\mathrm{CI}]$ ) is presented for each explanatory variable.

The multivariate logistic regression model (Pearson $\chi^{2}$ test) between HPV infection and the explanatory variables was adjusted for the variables used in the study design (age group and Regional Health Administration) and for the variables identified as statistically significant $(P<0.05)$ in the univariate analysis. Using a "forward conditional" method [11], explanatory variables demonstrating statistical significance in the univariate analyses were entered in sequence into the multivariate regression equation. A $P$ value of less than 0.05 was considered statistically significant.

\section{Results}

A total of 2372 women were invited to participate in the study and provided informed consent. One woman was withdrawn by one of the study investigators, and 45 women were excluded on the basis of the defined exclusion criteria. In all, 2326 women were included in the analysis; the mean age of the study group was $32.6 \pm$ 14.1 years, while the median age was 27 years. The majority of women were born in Portugal ( $n=2210 ; 95.0 \%) ; 800$ (34.4\%) had a university or college education; and $518(22.3 \%)$ were smokers. Over half of the study population had children $(n=1277 ; 54.9 \%)$ and 2072 (89.1\%) reported using contraception. Most women reported a single lifetime sexual partner ( $\mathrm{n}=1333 ; 57.3 \%) ; 2246$ (96.6\%) reported the absence of any STD in the past 12 months; 2234 (96.0\%) had no history of cervical intraepithelial neoplasia; and 2277 (97.9\%) were not currently immunocompromised.

The overall prevalence of HPV in the study sample was previously reported as $19.4 \%(n=451 ; 95 \%$ CI $17.8-21.0)$ [10]. Prevalence by age group ranged from 28.8\% (199/691) among women aged 20-24 years to $5.6 \%(11 / 196)$ among those aged $60-64$ years. High-risk HPV genotypes were identified in 76.5\% (345/451) of the HPV-positive women, with the highest prevalence among the younger age groups (18-29 years) [10]. Infection with multiple HPV genotypes was observed in $7.1 \%(165 / 2326)$ of the study population and $36.6 \%$ (165/451) of the HPV-positive women [10].

The results of the univariate logistic regression analysis of HPV infection status versus demographic, socioeconomic, lifestyle, and medical variables is shown in Table 1 . Young age increased the risk of HPV infection, with the highest risk occurring in the 20-24 years age group. Compared with the 60-64 years age group, the OR was 6.80 (95\% Cl, 0.87-3.90). Women born outside mainland Portugal also had an increased risk of HPV infection, as did women educated up to secondary school level.

Smoking was associated with an increased risk of HPV infection, with an OR of 2.18 (95\% CI, 1.73-2.75), while ex-smokers had a marginally increased risk (OR 1.13 ; 95\% CI, 0.80-1.59), although this finding was not statistically significant. Among current smokers, the risk of HPV infection increased with the number of cigarettes smoked. However, compared with women who had smoked for up to 10 years, women who had smoked for longer (11-20 years and $\geq 21$ years) had a lower risk of HPV infection. Young age at first sexual intercourse and a high lifetime number of sexual partners were both strongly associated with the prevalence of HPV infection. Use of contraception increased the risk of HPV infection (OR 2.12; 95\% CI, 1.40-3.20) as did having a circumcised sexual partner (OR 1.72, 95\% CI 1.27-2.34). Women without STDs in the past 12 months had a lower risk of HPV infection; the OR was 0.31 (95\% CI, 0.18-0.53).

The association between age and HPV infection remained statistically significant in the multivariate logistic regression analysis (Table 2). The highest risk of HPV infection was observed among women aged 20-24 years, whose risk of infection was 3-fold higher than that of women aged 60-64 years. The OR for this association was 3.02 (95\% CI, 1.52-6.00; $P=0.002$ ). Women born outside mainland Portugal showed a 2-fold higher risk of infection, with an OR of 2.00 (95\% CI, 1.30-3.06; $P=0.002$ ). Women educated up to basic or secondary school level continued to show an increased risk of HPV infection compared with women with a college or university education. The OR in the 12 th year was 1.47 (95\% CI, $1.11-1.95 ; P=0.007)$, while the OR in the 9th year was 1.57 (95\% CI, 1.16-2.13, $P=0.004)$. Similarly, women smoking for longer than 10 years continued to show a 
Table 1

Univariate logistic regression analysis between HPV infection and the explanatory variables.

\begin{tabular}{|c|c|c|c|c|}
\hline Explanatory variable & No. of participants & HPV positive (any genotype) ${ }^{a}$ & OR $(95 \% \mathrm{CI})^{\mathrm{b}}$ & $P$ value \\
\hline Age, y & 2326 & & & $<0.001$ \\
\hline $60-64$ & 196 & $11(5.6)$ & 1.00 & \\
\hline $50-59$ & 228 & $13(5.7)$ & $1.02(3.20-12.09)$ & \\
\hline $40-49$ & 223 & $22(9.9)$ & $1.84(3.62-12.77)$ & \\
\hline $30-39$ & 256 & $32(12.5)$ & $2.40(2.46-8.98)$ & \\
\hline $25-29$ & 458 & $100(21.8)$ & $4.70(1.18-4.90)$ & \\
\hline $20-24$ & 691 & $199(28.8)$ & $6.80(0.87-3.90)$ & \\
\hline $18-19$ & 274 & $74(27.0)$ & $6.22(0.45-2.32)$ & \\
\hline Country of birth & 2326 & & & $<0.001$ \\
\hline Portugal & 2210 & $400(18.1)$ & 1.00 & \\
\hline Other & 116 & $51(44.0)$ & $3.55(2.42-5.20)$ & \\
\hline Level of education & 2323 & & & $<0.001$ \\
\hline University/college & 800 & $144(18.0)$ & 1.00 & \\
\hline Secondary school (10th-12th year) & 587 & $155(26.4)$ & $1.64(1.26-2.11)$ & \\
\hline Basic school (5th-9th year) & 500 & $119(23.8)$ & $1.42(1.08-1.87)$ & \\
\hline Primary school (1st-4th year) & 351 & $30(8.5)$ & $0.43(0.28-0.65)$ & \\
\hline No formal education or incomplete (4th year) & 85 & $3(3.5)$ & $0.17(0.05-0.54)$ & \\
\hline Smoking status & 2311 & & & $<0.001$ \\
\hline Never smoked & 1524 & $246(16.1)$ & 1.00 & \\
\hline Current smoker & 518 & $153(29.5)$ & $2.18(1.73-2.75)$ & \\
\hline Ex-smoker & 269 & $48(17.8)$ & $1.13(0.80-1.59)$ & \\
\hline Current smokers: length of smoking history, y & 512 & & & $<0.001$ \\
\hline $1-10$ & 385 & $137(35.6)$ & 1.00 & \\
\hline $11-20$ & 79 & $11(13.9)$ & $0.29(0.15-0.57)$ & \\
\hline$\geq 21$ & 48 & $5(10.4)$ & $0.21(0.08-0.54)$ & \\
\hline Current smokers: no. of cigarettes smoked & 518 & & & 0.380 \\
\hline$<7$ weekly & 91 & $21(23.1)$ & 1.00 & \\
\hline 1-9 daily & 231 & $68(29.4)$ & $1.39(0.79-2.44)$ & \\
\hline $10-20$ daily & 178 & $57(32.0)$ & $1.57(0.90-2.81)$ & \\
\hline$>20$ daily & 18 & $7(38.9)$ & $2.12(0.73-6.16)$ & \\
\hline Age at first sexual intercourse, y & 948 & & & $<0.001$ \\
\hline$\geq 25$ & 30 & $4(13.3)$ & 1.00 & \\
\hline $21-24$ & 113 & $15(13.3)$ & $1.00(0.30-3.25)$ & \\
\hline $19-20$ & 162 & $39(24.1)$ & $2.06(0.68-6.27)$ & \\
\hline $17-18$ & 351 & $89(25.4)$ & $2.21(0.75-6.50)$ & \\
\hline $15-16$ & 230 & $64(27.8)$ & $2.51(0.84-7.46)$ & \\
\hline$\leq 14$ & 62 & $25(40.3)$ & $4.39(1.37-14.13)$ & \\
\hline Prior pregnancies & 2326 & & & $<0.001$ \\
\hline Yes & 1277 & $194(15.2)$ & 1.00 & \\
\hline No & 1049 & $257(24.5)$ & $1.81(1.47-2.23)$ & \\
\hline Contraceptive use & 2322 & & & 0.001 \\
\hline No & 250 & $27(10.8)$ & 1.00 & \\
\hline Yes & 2072 & $423(20.4)$ & $2.12(1.40-3.20)$ & \\
\hline \multicolumn{5}{|l|}{ Type of contraceptive } \\
\hline Oral contraceptive & 1778 & $377(21.2)$ & $1.45(1.04-2.03)$ & \\
\hline Intrauterine device & 203 & $23(11.3)$ & $0.47(0.30-0.73)$ & \\
\hline Condom & 618 & $133(21.5)$ & $1.10(0.87-1.39)$ & \\
\hline Tubal ligation & 102 & $6(5.9)$ & $0.23(0.10-0.54)$ & \\
\hline Other method & 63 & $3(4.8)$ & $0.19(0.06-0.61)$ & \\
\hline Lifetime number of sexual partners & 2287 & & & $<0.001$ \\
\hline 1 & 1333 & $131(9.8)$ & 1.00 & \\
\hline $2-4$ & 834 & $257(30.8)$ & $4.09(3.24-5.16)$ & \\
\hline $5-10$ & 120 & $58(48.3)$ & $8.58(5.75-12.82)$ & \\
\hline Any circumcised sexual partner & 2166 & & & 0.001 \\
\hline No & 1928 & $351(18.2)$ & 1.00 & \\
\hline Yes & 238 & $66(27.7)$ & $1.72(1.27-2.34)$ & \\
\hline Any sexually transmitted disease in the past $12 \mathrm{mo}$ & 2304 & & & $<0.001$ \\
\hline Yes & 58 & $25(43.1)$ & 1.00 & \\
\hline No & 2246 & $426(19.0)$ & $0.31(0.18-0.53)$ & \\
\hline Retroviral disease & 58 & & & $<0.001$ \\
\hline Yes & 7 & $1(14.3)$ & 1.00 & \\
\hline No & 51 & $24(47.1)$ & $5.33(0.60-47.52)$ & \\
\hline Herpes & 58 & & & $<0.001$ \\
\hline Yes & 7 & $3(42.9)$ & 1.00 & \\
\hline No & 51 & $22(43.1)$ & $1.01(0.21-4.99)$ & \\
\hline Genital warts & 58 & & & $<0.001$ \\
\hline Yes & 20 & $10(50.0)$ & 1.00 & \\
\hline No & 38 & $15(39.5)$ & $0.65(0.22-1.94)$ & \\
\hline Hepatitis & 58 & & & $<0.001$ \\
\hline Yes & 4 & $3(75.0)$ & 1.00 & \\
\hline No & 54 & $22(40.7)$ & $0.23(0.02-2.35)$ & \\
\hline Other sexually transmitted disease & 58 & & & $<0.001$ \\
\hline Yes & 23 & $11(47.8)$ & 1.00 & \\
\hline No & 35 & $14(40.0)$ & $0.73(0.25-2.10)$ & \\
\hline
\end{tabular}


Table 1 (continued)

\begin{tabular}{|c|c|c|c|c|}
\hline Explanatory variable & No. of participants & HPV positive (any genotype) ${ }^{a}$ & OR $(95 \% \mathrm{CI})^{\mathrm{b}}$ & $P$ value \\
\hline History of cervical intraepithelial neoplasia & 2298 & & & 0.878 \\
\hline No & 2234 & $436(19.5)$ & 1.00 & \\
\hline Yes & 64 & $12(18.8)$ & $0.95(0.50-1.80)$ & \\
\hline Currently immunocompromised & 2305 & & & 0.849 \\
\hline Yes & 28 & $5(17.9)$ & 1.00 & \\
\hline No & 2277 & $441(19.4)$ & $1.11(0.42-2.92)$ & \\
\hline
\end{tabular}

Abbreviations: CI, confidence interval; HPV, human papillomavirus; OR, odds ratio.

a Values are given as number (percentage).

b An OR of 1.00 represents the null hypothesis of no association.

lower risk of HPV infection than women who had smoked for up to 10 years. Among women who had smoked for 11-20 years, the OR was 0.42 (95\% CI, 0.20-0.87; $P=0.019$ ), whereas the OR for women who had smoked for 21 years or more was 0.50 (95\% CI, 0.18-1.41; not significant). A high lifetime number of sexual partners remained a significant predictor of HPV infection, with more than a 5-fold increased risk in women with 5-10 sexual partners compared with women reporting 1 lifetime sexual partner. The OR for this association was $5.44(95 \% \mathrm{Cl}, 3.51-8.43 ; P<0.001)$. Women reporting any STD in the past 12 months showed an increased risk of HPV infection

Table 2

Multivariate logistic regression analysis between HPV infection (any genotype) and the explanatory variables. ${ }^{\mathrm{a}}$

\begin{tabular}{|c|c|c|c|}
\hline Explanatory variable & $\begin{array}{l}\text { No. of } \\
\text { participants }\end{array}$ & OR $(95 \% \mathrm{CI})^{b}$ & $P$ value \\
\hline Age, y & 2295 & & $<0.001$ \\
\hline 60-64 & 192 & 1.00 & \\
\hline $50-59$ & 221 & $0.96(0.42-2.23)$ & \\
\hline $40-49$ & 215 & $1.36(0.62-2.97)$ & \\
\hline $30-39$ & 252 & $1.46(0.69-3.10)$ & \\
\hline $25-29$ & 456 & $2.32(1.15-4.67)$ & \\
\hline $20-24$ & 686 & $3.02(1.52-6.00)$ & \\
\hline $18-19$ & 273 & $2.50(1.22-5.13)$ & \\
\hline Country of birth & 2295 & & 0.002 \\
\hline Portugal & 2179 & 1.00 & \\
\hline Other & 116 & $2.00(1.30-3.06)$ & \\
\hline Level of education & 2295 & & 0.010 \\
\hline University/college & 791 & 1.00 & \\
\hline $\begin{array}{l}\text { Secondary school } \\
\text { (10th-12th year) }\end{array}$ & 583 & $1.47(1.11-1.95)$ & \\
\hline $\begin{array}{l}\text { Basic school } \\
\text { (5th-9th year) }\end{array}$ & 493 & $1.57(1.16-2.13)$ & \\
\hline $\begin{array}{l}\text { Primary school } \\
\text { (1st-4th year) }\end{array}$ & 344 & $1.10(0.68-1.77)$ & \\
\hline $\begin{array}{l}\text { No formal education } \\
\text { or incomplete } \\
\text { (4th year) }\end{array}$ & 84 & $0.53(0.16-1.82)$ & \\
\hline $\begin{array}{l}\text { Current smokers: length } \\
\text { of smoking history, } y\end{array}$ & 510 & & 0.004 \\
\hline $1-10$ & 384 & 1.00 & \\
\hline $11-20$ & 78 & $0.42(0.20-0.87)$ & \\
\hline$\geq 21$ & 48 & $0.50(0.18-1.41)$ & \\
\hline $\begin{array}{l}\text { Lifetime number of } \\
\text { sexual partners }\end{array}$ & 2260 & & $<0.001$ \\
\hline 1 & 1312 & 1.00 & \\
\hline $2-4$ & 828 & $3.10(2.42-3.97)$ & \\
\hline $5-10$ & 120 & $5.44(3.51-8.43)$ & \\
\hline $\begin{array}{l}\text { Any sexually transmitted } \\
\text { disease in the past } \\
12 \text { mo }\end{array}$ & 2295 & & 0.052 \\
\hline No & 2237 & 1.00 & \\
\hline Yes & 58 & $1.79(1.00-3.23)$ & \\
\hline
\end{tabular}

Abbreviations: CI, confidence interval; HPV, human papillomavirus; OR, odds ratio.

a The multivariate logistic regression analysis was adjusted for age group and Regional Health Administration. Explanatory variables were identified as statistically significant $(P<0.05)$ in the univariate analysis.

b An OR of 1.00 represents the null hypothesis of no association. Model evaluation: $P=0.368$ (Hosmer and Lemeshow test); $P<0.001$ (omnibus test of model coefficients); Nagelkerke $R^{2}=0.205$.
(OR 1.79; 95\% CI 1.00-3.23) and this observation bordered on statistical significance $(P=0.052)$.

\section{Discussion}

A risk factor analysis was carried out as part of the CLEOPATRE Portugal study, a population-based study that aims to evaluate the prevalence of cervical HPV infection among women living in mainland Portugal [10]. The present study evaluated a range of demographic, socioeconomic, lifestyle, and medical variables for their potential to predict the likelihood of HPV infection. The variables identified as risk factors for HPV infection were young age; country of birth other than Portugal; secondary level of education; a smoking history of up to 10 years; a high lifetime number of sexual partners; and any STD in the last 12 months.

The risk of HPV infection was highest among women aged 20-24 years but declined with increasing age. The identification of age as a significant predictor of HPV infection was expected, as it is well recognized that young adults have an increased risk of acquiring HPV, and that HPV prevalence decreases with age [12-14]. In Latin American countries, a second peak of HPV prevalence has been detected among older age groups ( $\geq 45$ years) $[15,16]$. In agreement with other European data [12,16], no second prevalence peak was observed in the present study [10].

Lifetime number of sexual partners was identified as a strong determinant of HPV infection in the multivariate analysis. Women reporting 5-10 sexual partners had a 5.44-fold higher risk of infection than women reporting 1 partner. This observation is consistent with the findings of an Italian study conducted in women aged 18-24 years, which showed that women with 5 or more sexual partners in the previous 3 years had a 6.8 -fold increased risk of infection compared with women with 1 partner [17].

In terms of smoking habits, there was an apparent protective effect among women who had been smoking for more than 10 years compared with women who had been smoking for a shorter period of time. The number of cigarettes smoked each day or week did not affect the risk of HPV infection in the multivariate analysis. These findings differ from those of other studies that have examined the relationship between smoking and HPV infection. The study in young women in Italy [17] demonstrated a 2-fold higher risk of infection among women smoking more than 10 cigarettes per day compared with non-smokers. Similarly, after adjusting for the lifetime number of sexual partners in a pooled analysis by the International Agency for Research on Cancer (IARC), the risk of HPV infection increased with smoking intensity [9]. The increased prevalence of HPV infection observed in women with a shorter versus a longer smoking history in the present study would suggest that the effects of age may be overriding the effects of smoking.

Compared with women born in mainland Portugal, the risk of HPV infection was doubled among women born elsewhere. The most frequent countries of birth other than Portugal, in descending order, were Portuguese-speaking African countries, Brazil, and eastern European countries. This finding might be related to the fact that the adjusted HPV prevalence is high in these regions [15]. 
Analysis of the impact of education level on the acquisition of HPV infection revealed that women educated up to secondary school level had the highest risk of infection. In an analysis of data from 2 large multicenter IARC studies, no association between education level and HPV infection emerged [18]. Education level alone is an inadequate measure of socioeconomic status, which is influenced by a combination of other factors. In the IARC analysis [18], an increase in the incidence of cervical cancer among women of low socioeconomic status was attributed largely to age at first sexual intercourse, age at first pregnancy, and parity. The association between secondary level education and HPV infection observed in the present study is probably related to age, with younger women being more likely to report attainment of secondary level education.

As for similar studies, there are some potential limitations and a risk of data bias in the present study, particularly in relation to the explanatory variables "age at first sexual intercourse," "lifetime number of sexual partners," and "any circumcised sexual partner." These variables cover aspects of sexual behavior that women may feel sensitive about, or be uninformed about, and the responses to these questions may not have been answered accurately by some women. Data collection for the variable "age at first sexual intercourse" was introduced after the study had already started, and therefore early study entrants were not questioned on this variable. Although this variable was statistically significant in the univariate model, it was excluded from the multivariate analysis because the number of responses was low. The questions relating to "any circumcised sexual partner" (small number of cases to draw conclusions) and "contraceptive use" were considered to have been formulated inadequately. As a consequence, the risks associated with these variables should be interpreted with caution.

In conclusion, the CLEOPATRE Portugal study has identified a number of demographic, socioeconomic, lifestyle, and medical factors that may help predict cervical HPV infection among women in Portugal. Lifetime number of sexual partners was identified as a major risk factor for HPV infection. Other notable risk factors were birth in countries other than mainland Portugal and a history of any STD in the past 12 months. These data will contribute to a better understanding of the wide spectrum of HPV infection across Europe, and may contribute to the identification of women at increased risk of HPV infection.

\section{Acknowledgments}

The study was sponsored by Sanofi Pasteur.

\section{Conflict of interest}

The National Institute of Health (INSA), the sponsor, and the CLEOPATRE Portugal study coordinators were involved in the study design, database analysis, and preparation and review of the manuscript. A.P. received a travel grant from Sanofi Pasteur MSDPortugal; C.F. de O. received a travel grant and hotel expenses from Sanofi Pasteur MSD-Portugal; M.J.C. is an employee in the Medical Department of Sanofi Pasteur MSD-Portugal; M.T.P. has acted as an advisory board member for Sanofi Pasteur MSD-Portugal.

\section{References}

[1] Walboomers JM, Jacobs MV, Manos MM, Bosch FX, Kummer JA, Shah KV, et al Human papillomavirus is a necessary cause of invasive cervical cancer worldwide. J Pathol 1999;189(1):12-9.

[2] Smith JS, Lindsay L, Hoots B, Keys J, Franceschi S, Winer R, et al. Human papillomavirus type distribution in invasive cervical cancer and high-grade cervical lesions: a meta-analysis update. Int J Cancer 2007;121(3):621-32.

[3] von Krogh G. Management of anogenital warts (condylomata acuminata). Eur J Dermatol 2001:11(6):598-603.

[4] Ammatuna P, Giovannelli L, Matranga D, Ciriminna S, Perino A. Prevalence of genital human papilloma virus infection and genotypes among young women in Sicily, South Italy. Cancer Epidemiol Biomarkers Prev 2008;17(8):2002-6.

[5] Karlsson R, Jonsson M, Edlund K, Evander M, Gustavsson A, Bodén E, et al. Lifetime number of partners as the only independent risk factor for human papillomavirus infection: a population-based study. Sex Transm Dis 1995;22(2):119-27.

[6] Vaccarella S, Franceschi S, Herrero R, Muñoz N, Snijders PJ, Clifford GM, et al. Sexual behavior, condom use, and human papillomavirus: pooled analysis of the IARC human papillomavirus prevalence surveys. Cancer Epidemiol Biomarkers Prev 2006;15(2):326-33.

[7] Muñoz N, Kato I, Bosch FX, Eluf-Neto J, De Sanjosé S, Ascunce N, et al. Risk factors for HPV DNA detection in middle-aged women. Sex Transm Dis 1996;23(6): 504-10.

[8] Vaccarella S, Herrero R, Dai M, Snijders PJ, Meijer CJ, Thomas JO, et al. Reproductive factors, oral contraceptive use, and human papillomavirus infection: pooled analysis of the IARC HPV prevalence surveys. Cancer Epidemiol Biomarkers Prev 2006;15(11):2148-53.

[9] Vaccarella S, Herrero R, Snijders PJ, Dai M, Thomas JO, Hieu NT, et al. Smoking and human papillomavirus infection: pooled analysis of the International Agency for Research on Cancer HPV Prevalence Surveys. Int J Epidemiol 2008;37(3):536-46.

[10] Pista A, de Oliveira CF, Cunha MJ, Paixao MT, Real O, CLEOPATRE Portugal Study Group. Prevalence of human papillomavirus infection in women in Portugal: the CLEOPATRE Portugal study. Int J Gynecol Cancer 2011;21(6):1150-8.

[11] Grechanovsky E, Pinsker I. Conditional p-values for the F-statistic in a forward selection procedure. Comput Stat Data Anal 1995;20(3):239-63.

[12] Kjaer SK, Breugelmans G, Munk C, Junge J, Watson M, Iftner T. Population-based prevalence, type- and age-specific distribution of HPV in women before introduction of an HPV-vaccination program in Denmark. Int J Cancer 2008;123(8): 1864-70.

[13] Ronco G, Ghisetti V, Segnan N, Snijders PJ, Gillio-Tos A, Meijer CJ, et al. Prevalence of human papillomavirus infection in women in Turin, Italy. Eur J Cancer 2005;41(2):297-305

[14] Uusküla A, Kals M, Kosenkranius L, McNutt LA, DeHovitz JJ. Population-based type-specific prevalence of high-risk human papillomavirus infection in Estonia. BMC Infect Dis 2010;10:63.

[15] de Sanjosé S, Diaz M, Castellsagué X, Clifford G, Bruni L, Muñoz N, et al. Worldwide prevalence and genotype distribution of cervical human papillomavirus DNA in women with normal cytology: a meta-analysis. Lancet Infect Dis 2007;7(7):453-9.

[16] Franceschi S, Herrero R, Clifford GM, Snijders PJ, Arslan A, Anh PT, et al. Variations in the age-specific curves of human papillomavirus prevalence in women worldwide. Int J Cancer 2006;119(11):2677-84.

[17] Confortini M, Carozzi F, Zappa M, Ventura L, Iossa A, Cariaggi P, et al. Human papillomavirus infection and risk factors in a cohort of Tuscan women aged 18-24: results at recruitment. BMC Infect Dis 2010;10:157.

[18] Franceschi S, Plummer M, Clifford G, de Sanjose S, Bosch X, Herrero R, et al. Differences in the risk of cervical cancer and human papillomavirus infection by education level. Br J Cancer 2009;101(5):865-70. 